\title{
Osteoprotective Effects of IL-33/ST2 Link to Osteoclast Apoptosis
}

Izabella L.A. Lima, ${ }^{\star}$ Soraia Macari, ${ }^{*}$ Mila F.M. Madeira, ${ }^{\dagger}$ Letícia F.D. Rodrigues, ${ }^{\dagger}$ Priscila M. Colavite, ${ }^{\ddagger}$ Gustavo P. Garlet, Frederico M. Soriani, ${ }^{\S}$ Mauro M. Teixeira, ${ }^{*}$ Sandra Y. Fukada, ${ }^{\top}$ and Tarcília A. Silva

From the Departments of Biochemistry and Immunology* and General Biology, ${ }^{\S}$ Institute of Biological Sciences, and the Department of Oral Pathology, ${ }^{\dagger}$ Faculty of Dentistry, Federal University of Minas Gerais, Belo Horizonte, Minas Gerais; the Department of Biological Sciences, ${ }^{\ddagger}$ Bauru School of Dentistry, University of São Paulo, Bauru, São Paulo; and the School of Medicine of Ribeirao Preto, and the Department of Physics and Chemistry, ${ }^{\top}$ Faculty of Pharmaceutical Sciences of Ribeirão Preto, São Paulo University, São Paulo, Brazil

Accepted for publication August 4, 2015.

Address correspondence to Tarcília A. Silva, Ph.D., Departamento de Clínica, Patologia e Cirurgia Odontológicas, Faculdade de Odontologia, Universidade Federal de Minas Gerais, Ave Presidente Antônio Carlos 6627, CEP 31.270-901, Belo Horizonte, Minas Gerais, Brazil. E-mail: tarcilia@ufmg. br.

\begin{abstract}
The relevance of IL-33 and its receptor ST2 for bone remodeling is not well-defined. Our aim was to assess the role and underlying mechanisms of IL-33/ST2 in mechanically induced bone remodeling. BALB/c (wild type) and ST2 deficient (St2 ${ }^{-/}$) mice were subjected to mechanical loading in alveolar bone. Microtomography, histology, and real-time quantitative PCR were performed to analyze bone parameters, apoptosis and bone cell counts, and expression of bone remodeling markers, respectively. MC3T3-E1 osteoblastic cells and bone marrow cells were used to verify if mechanical force triggered IL-33 and ST2 expression as well as the effects of IL-33 on osteoclast differentiation and activity. Mechanical loading increased the expression of IL-33 and ST2 in alveolar bone in vivo and in osteoblastic cells in vitro. St2 ${ }^{-1-}$ mice had increased mechanical loading-induced bone resorption, number of osteoclasts, and expression of proresorptive markers. In contrast, St2 ${ }^{-1-}$ mice exhibited reduced numbers of osteoblasts and apoptotic cells in periodontium and diminished expression of osteoblast signaling molecules. In vitro, IL-33 treatment inhibited osteoclast differentiation and activity even in the presence of receptor activator of NF- $\kappa B$ ligand. IL-33 also increased the expression of pro-apoptotic molecules, including Bcl-2-associated X protein (BAX), cell-surface Fas receptor (FAS), FASL, FAS-associated death domain, tumor necrosis factor-related apoptosis-inducing ligand, and BH3 interacting-domain death (BID). Overall, these findings suggest that IL-33/ST2 have anti-osteoclastogenic effects and reduce osteoclast formation and activity by inducing their apoptosis. (Am J Pathol 2015, 185: 3338-3348; http://dx.doi.org/10.1016/ j.ajpath.2015.08.013)
\end{abstract}

Bone remodeling is a strictly coordinated physiological process of bone resorption and apposition. This process, coordinated by traditional bone cells, is responsible for maintenance of homeostasis and restoration of any bone damage. ${ }^{1}$ The function of bone cells is influenced by several factors, including growth factors, ${ }^{2}$ hormones, ${ }^{3}$ diet, ${ }^{4}$ and cytokines. ${ }^{5}$ The cytokine IL-33 has been recently implicated in physiological bone remodeling. ${ }^{6}$

IL-33 belongs to the IL-1 family ${ }^{6}$ and is constitutively expressed in different organs and tissues (eg, connective, lung, endothelium, and synovial tissues). ${ }^{7-10} \mathrm{IL}-33$ is also released in response to tissue damage as an alarmin. ${ }^{6}$ IL-33 functions are associated with type 2 helper T-cell immune response, ${ }^{7-9}$ induction of cell division, ${ }^{10}$ apoptosis, ${ }^{11}$ and regulation of bone resorption. $^{12-15} \mathrm{IL}-33$ and its receptor $\mathrm{ST} 2^{16}$ are expressed by osteoclasts, ${ }^{9,12-15,17,18}$ osteoblasts, ${ }^{19,20}$ and osteocytes. ${ }^{19}$ The role of IL-33/ST2 in the context of bone physiology is controversial. It may suppress bone resorption ${ }^{13-15,21}$ but also stimulate osteoclast formation, independent of the receptor activator of NF- $\kappa \mathrm{B}$ (RANK) and the RANK ligand (RANKL) system. $^{17}$

A few studies have shown that increase of IL-33 levels in gingival crevicular fluid ${ }^{22}$ and periodontal tissues ${ }^{23}$ during inflammatory conditions is associated with alveolar bone loss. Herein, we used a model of bone remodeling induced by

Supported by Fundação de Amparo a Pesquisas do Estado de Minas Gerais (00276-13; Brazil), Coordenação de Aperfeiçoamento de Pessoal de Nível Superior (2245/2011), and Conselho Nacional de Desenvolvimento Científico e Tecnológico (306982/2013; Brazil).

Disclosures: None declared. 
mechanical loading to investigate the role of IL-33/ST2 axis in the alveolar bone. We hypothesized that mechanically stressed cells in periodontium release IL-33, which functions as a stop signal for osteoclasts.

\section{Materials and Methods}

\section{Experimental Animals}

Fifty 10-week-old wild-type (WT; BALB/c) and 40 ST2deficient mice $\left(\mathrm{St}^{-/-}\right)$from Universidade de São Paulo (São Paulo, Brazil) and Universidade Federal de Minas Gerais (Minas Gerais, Brazil) were included in this study. All animals were treated under Institutional Ethics Committee regulations for animal experiments (protocol 130/ 2012). For every set of experiments, five mice were used for each time point. Each animal weight was recorded throughout the experimental period, in which no significant weight loss was observed. Mice were maintained under standard conditions with a 12-hour light/dark cycle, controlled temperature $\left(24^{\circ} \mathrm{C} \pm 2^{\circ} \mathrm{C}\right)$, and free access to commercial chow and drinking water.

\section{Experimental Protocol for Bone Remodeling Induced by OTM}

The experimental protocol was on the basis of a previous study. ${ }^{24}$ Briefly, a coil was bonded between the maxillary right first molar and incisors. The force magnitude was set at $0.35 \mathrm{~N}$, applied in a mesial direction. The coil was not reactivated during the experimental period. The left side of the maxilla was used as control. Orthodontic tooth movement (OTM) was obtained through the difference between the distance of the cemento-enamel junction of first and second molar of the experimental side (right hemimaxilla) in relation to the control side (left hemimaxilla) of the same animal. The measurements were obtained by microcomputed tomography (MicroCT) image and then maxillae were also submitted to histological analysis. Three measurements were conducted for each evaluation, and the variability was $<5 \%$.

\section{MicroCT Imaging}

Maxillae were scanned with Skyscan 1176 (Bruker-MicroCT, Kontich, Belgium). A $12.45-\mu \mathrm{m}$ camera pixel size with camera XY ratio of 0.9870 , voltage of $50 \mathrm{kV}$, and current of $500 \mu \mathrm{A}$ was used. A filter of $0.5 \mathrm{~mm}$ was used, and scanning trajectory was round. Results were analyzed using Dataviewer 32-bit version and CTAn 32-bit version software (Bruker-MicroCT). Maxillae were analyzed in fixed coronal and sagittal zones. Bone phenotype was evaluated in maxillae and proximal femurs on all planes. The parameters evaluated were trabecular thickness, trabecular number, trabecular separation, percentage bone volume, bone surface density, bone surface, bone mineral density, tissue mineral density, and cross-sectional thickness.

\section{Samples}

We have standardized a method for including and cutting samples. ${ }^{24}$ The anterior maxilla fragment containing the incisors was removed with a scalpel, and the scalpel was positioned in the palatal suture separating the maxilla in right and left halves. Right and left maxilla halves, including first, second, and third molars, were dissected, fixed in $10 \%$ buffered formalin, decalcified in 14\% EDTA (pH 7.4) for 21 days, and embedded in paraffin. The entire blocks containing the samples were cut into sagittal sections. After roughing the microtome approximately 120 times of $10 \mu \mathrm{m}$ thickness, sections ( $4 \mu \mathrm{m}$ thick) were obtained. The sections selected for hematoxylin and eosin, histochemistry, and immunohistochemistry presented the first and second molars, their mesial and distal-buccal root, the third molar, and adjacent structures, including the periodontal ligament and alveolar bone. At least five serial vertical sections containing the above mentioned structures were evaluated for each animal for each analysis.

\section{Immunohistochemistry}

Immunohistochemistry was performed using maxillae sections to evaluate ST2 expression. Sections were deparaffinized, dehydrated, and rinsed in distilled water and incubated with $0.3 \%$ hydrogen peroxide twice for 15 minutes. For antigen retrieval, the slides were immersed in citric acid buffer $(\mathrm{pH}$ 6.0) at $96^{\circ} \mathrm{C}$ for 30 minutes. Sections were incubated with T1/ST2 (IL-33R) monoclonal antibody (Bioscience, San Jose, CA) at 1:100 dilution overnight. Then, the secondary antibody (kit LSAB; Dako, Glostrup, Denmark) was used according to the manufacturer's instructions. The immunolabeling was visualized after incubation with 3,3-diaminobenzidine solution (Dako). Negative controls were obtained by omission of the primary antibody, and were substituted by $0.1 \%$ phosphatebuffered saline--bovine serum albumin.

\section{Bone Cell Counting}

The distal-buccal root of the first molar, on its coronal twothirds of the mesial periodontal site, was used for counting osteoclasts, which were stained for tartrate-resistant acid phosphatase (TRAP; Sigma-Aldrich, St. Louis, MO). Osteoclasts were identified as TRAP-positive, multinucleated cells seated on the bone surface.

The distal bone of the first molar distal-buccal root, on its mesiocoronal two-thirds, was used for osteoblast counting, stained with Masson's trichrome.

\section{Apoptotic Cells}

Terminal deoxynucleotidyl-transferase-mediated dUTPFITC nick-end labeling (Calbiochem, Darmstadt, Germany) was used for identification of apoptotic cells on the mesial bone of the first molar distal-buccal root, on its mesiocoronal two-thirds. 
Table 1 Parameters Related to Bone Mineral Density Obtained by MicroCT of Femurs and Maxillary Bones of WT and ST2 Deficient Mice

\begin{tabular}{lllll}
\hline Bone analyzed & Parameters & WT, means \pm SEM & St2 $^{-/-}$, means \pm SEM & $P$ value \\
\hline Femur & Tb.N $\left(\mu \mathrm{m}^{-1}\right)$ & $1.90 \times 10^{-2} \pm 2.00 \times 10^{-3}$ & $1.5 \times 10^{-2} \pm 1.00 \times 10^{-3}$ & $0.0363^{*}$ \\
& Tb.Sp $(\mu \mathrm{m})$ & $42.92 \pm 0.49$ & $47.98 \pm 3.31$ & $0.0100^{*}$ \\
& BV/TV $(\%)$ & $21.96 \pm 1.36$ & $16.64 \pm 0.65$ & $0.0036^{*}$ \\
Maxilla & BS $\left(\mu \mathrm{m}^{2}\right)$ & $59.61 \times 10^{4} \pm 5.09 \times 10^{4}$ & $45.09 \times 10^{4} \pm 2.46 \times 10^{4}$ \\
& Tb.N $\left(\mu \mathrm{m}^{-1}\right)$ & $3.54 \times 10^{-3} \pm 2.75 \times 10^{-4}$ & $3.27 \times 10^{-3} \pm 1.00 \times 10^{-4}$ & 0.6990 \\
& Tb.Sp $(\mu \mathrm{m})$ & $139.80 \pm 3.82$ & $120.60 \pm 14.61$ & 0.1200 \\
& BV/TV $(\%)$ & $78.47 \pm 0.69$ & $74.03 \pm 0.37$ & $0.0332^{*}$ \\
& BS $\left(\mu \mathrm{m}^{2}\right)$ & $15.99 \times 10^{5} \pm 37.84 \times 10^{4}$ & $15.57 \times 10^{5} \pm 17.32 \times 10^{4}$ \\
\hline
\end{tabular}

$* P<0.05$.

BS, bone surface; BV/TV, bone volume; MicroCT, microcomputed tomography; Tb.N, trabecular number; Tb.Sp, trabecular separation; WT, wild type.

\section{Enzyme-Linked Immunosorbent Assay}

By using a stereomicroscope, periodontal ligament and surrounding alveolar bone samples were extracted from the upper first molar. The samples were obtained from WT mice after 0,12 , and 72 hours of mechanical loading. Tissues were weighed and diluted in phosphate-buffered saline $(0.4$ $\mathrm{mmol} / \mathrm{L} \mathrm{NaCl}$ and $\left.10 \mathrm{mmol} / \mathrm{L} \mathrm{NaPO}_{4}\right)$ containing protease inhibitors $(0.1 \mathrm{mmol} / \mathrm{L}$ phenylmethylsulfonyl fluoride, 0.1 $\mathrm{mmol} / \mathrm{L}$ benzethonium chloride, $10 \mathrm{mmol} / \mathrm{L}$ EDTA, and $0.01 \mathrm{mg} / \mathrm{mL}$ aprotinin A) and $0.05 \%$ Tween 20 at $1 \mathrm{mg} / \mathrm{mL}$. The mixture was centrifuged $(10,000 \times g)$ for 10 minutes. The supernatant was collected and stored at $-80^{\circ} \mathrm{C}$ for further analysis. The concentration $(\mathrm{pg} / \mathrm{mL})$ of IL-33 was evaluated by enzyme-linked immunosorbent assay, according to the manufacturer's protocol (R\&D Systems, Minneapolis, MN). The results were expressed as picograms of cytokine per $100 \mathrm{mg}$ tissue.

\section{Real-Time PCR}

As described above, periodontal ligament and surrounding alveolar bone samples were obtained from upper first molars. Whole alveolar samples, periodontal tissues, and alveolar bone extracted from the distal area of the distal-buccal root of the first molar were also collected in a separate set of experiments and considered samples preferentially subjected to tension forces, for measuring the expression of osteoblast markers. Similarly, the medial region of the mesial root of the first molar was collected separately, corresponding to a region of pressure strain, for measuring the expression of osteoclast markers. Samples were harvested after 0, 12, and 72 hours of mechanical loading and total RNA extracted (RNeasy FFPE kit; Qiagen Inc., Valencia, CA), according to the manufacturer's instructions. The integrity of RNA samples was checked by analyzing $1 \mathrm{mg}$ of total RNA on a 2100 Bioanalyzer (Agilent Technologies, Santa Clara, CA). The cDNA was synthesized using $3 \mu \mathrm{g}$ of RNA through a reverse transcription reaction (Superscript III; Invitrogen Corp., Carlsbad, CA). A real-time PCR array was performed in a Viia7 instrument (Life Technologies, Rockville, MD) using TaqMan chemistry (Invitrogen Corp.) associated with inventoried optimized primer/probe sets (Invitrogen Corp.), with basic reaction conditions of (40 cycles) $95^{\circ} \mathrm{C}$ (10 minutes), $94^{\circ} \mathrm{C}$ ( 1 minute), $56^{\circ} \mathrm{C}$ ( 1 minute), and $72^{\circ} \mathrm{C}$ ( 2 minutes). The mean $\mathrm{Ct}$ values from duplicate measurements were used to calculate expression of the target gene, with normalization to an internal control ( $\beta$-actin) using the $2^{-\Delta \Delta C t}$ method.

Samples from osteoblast culture were also submitted to RNA extraction using Trizol (Life Technologies). The cDNA was synthesized using SuperScript III Reverse Transcriptase (Invitrogen Corp.), and real-time PCRs were performed in an Applied Biosystems 7500 FAST device, and detected by SYBR Green (Applied Biosystems, Foster City, CA). Briefly, reactions were performed in a $10 \mu \mathrm{L}$ final volume containing $5 \mu \mathrm{L}$ of SYBR Green Master mix, $1 \mu \mathrm{L}$ of each primer $(5 \mu \mathrm{mol} / \mathrm{L}), 2 \mu \mathrm{L}$ of deionized water, and $1 \mu \mathrm{L}$ of cDNA. The reactions were initialized with $60^{\circ} \mathrm{C}$ for 20 seconds, followed by a step of $95^{\circ} \mathrm{C}$ for 10 minutes, 40 cycles at $95^{\circ} \mathrm{C}$ for 10 seconds, and $60^{\circ} \mathrm{C}$ for 1 minute. At the end of reactions, a melting curve was performed. $18 \mathrm{~S}$ was used as a housekeeping reference gene. Results were analyzed using the $2^{-\Delta \Delta C t}$ method, and IL-33 and ST2 were expressed as fold increase.

Samples from osteoclast cultures were analyzed to quantify mRNA expression of apoptotic markers using PCR Array (SA Biosciences/Qiagen Inc., Frederick, MD) and an apoptosis focused panel (PAMM-012Z), according to the manufacturer's guidelines. The results were analyzed by RT2 profiler PCR Array Data Analysis online software version 3.5 (SA Biosciences/Qiagen Inc.; http://pcrdataanalysis.sabiosciences. com/pcr/arrayanalysis.php, last accessed August 4, 2015), which used $2^{-\Delta \Delta C t}$ for normalizing the initial geometric average of three housekeeping genes $(G A P D H, A C T B$, and $H P R T 1$ ) subsequently normalized by control group and expressed as fold change.

\section{Osteoblast Cultures-Exposure of Bone Cells to Fluid Flow}

The well-characterized cell line with osteoblastic phenotype MC3T3-E ${ }^{25}$ was cultured in $\alpha$-minimal essential medium (Invitrogen Corp.) media containing 10\% fetal bovine serum (ATCC, Manassas, VA) and 1\% penicillin-streptomycin (Invitrogen Corp.) at $37^{\circ} \mathrm{C}$ in a $5 \% \mathrm{CO}_{2}$ humidified incubator. The cells were subcultured on quartz slides coated with fibronectin 72 hours before experimentation. Approximately $1.5 \times 10^{8}$ 
A
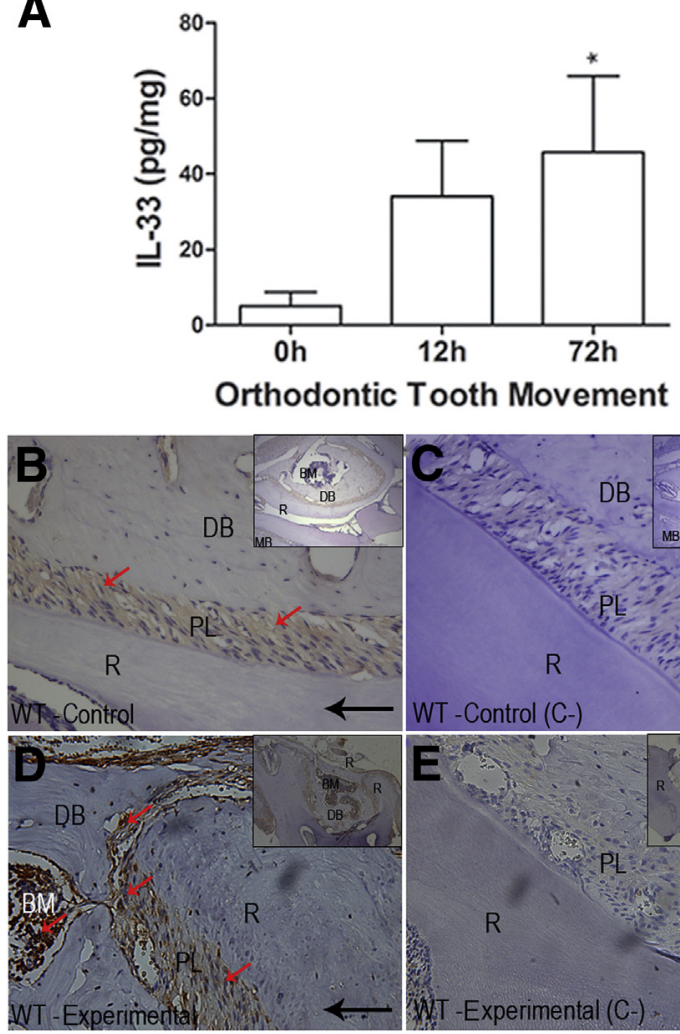

$\mathbf{F}$

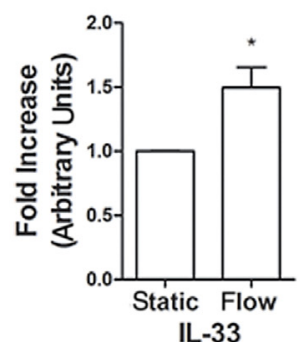

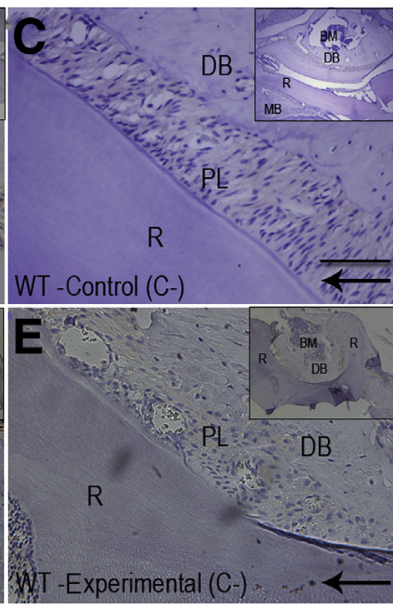

G

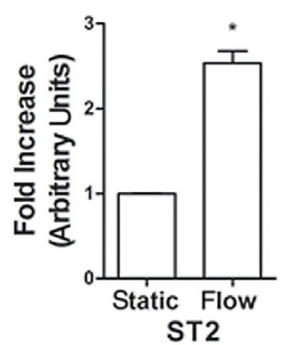

Figure 1 Expression of IL-33 and its receptor ST2 in vivo and in vitro. A: IL-33 concentration in periodontium of BALB/C mice after 12 and 72 hours of mechanical loading. B-E: Representative images of ST2 immunoexpression in maxillae of control (B and $\mathbf{C}$ ) and experimental ( $\mathbf{D}$ and $\mathbf{E})$ mice. C and E: Negative controls of immunohistochemistry ( $C-$ ). Red arrows show ST2 positivity; black arrows, the direction of tooth movement. $\mathbf{F}$ and G: Expression of IL-33 and ST2 by MC3T3-E1 osteoblastic cells under fluid flow and static in vitro conditions. Data were expressed as means $\pm \mathrm{SEM}$ $(\mathbf{A}, \mathbf{F}$, and $\mathbf{G}) .{ }^{*} P<0.05$. Scale bar $=100 \mu \mathrm{m}$ (C). Original magnification, $\times 10$ (B-E, insets). $B M$, bone marrow; $D B$, distal alveolar bone; MB, mesial alveolar bone; $\mathrm{PL}$, periodontal ligament; $\mathrm{R}$, root; $\mathrm{WT}$, wild type.

beads $/ \mathrm{mL}$ suspension of $1-\mu \mathrm{m}$-diameter sulfate-coated, $1-\mu \mathrm{m}$-diameter collagen $\mathrm{I}-$ coated, or $2-\mu \mathrm{m}$-diameter collagen I-coated fluorescent polystyrene beads (Molecular Probes, Eugene, OR) was added to each slide. The cells were incubated for approximately 1 hour to allow attachment and rinsed with phosphate-buffered saline to remove unbound beads. The beads were incubated in serum-free conditions to minimize the potential for proteins to adsorb onto the surface of beads before binding to the cell. The cells were loaded into a parallel-plate flow chamber and exposed to 10 seconds of sinusoidal oscillatory fluid flow, resulting in 1.0-Pa peak shear stress at

frequencies of $0.5,1.0$, or $2.0 \mathrm{~Hz}$, or 10 seconds of steady fluid flow resulting in 1.0-Pa shear stress. Real-time PCR was then performed to determinate IL-33 and ST2 mRNA expression using osteoblastic cells exposed to fluid flow (experimental group) and under static conditions (control group).

\section{Osteoclast Cultures}

Bone marrow cells were isolated from femur and tibia of BALB/c mice and cultured in Dulbecco's modified Eagle's medium (Gibco, Carlsbad, CA), supplemented with 10\% heat-inactivated fetal bovine serum, $40 \mathrm{U} / \mathrm{mL}$ penicillin, and $40 \mathrm{mg} / \mathrm{mL}$ gentamicin. Cells were grown in a humidified atmosphere containing $5 \% \mathrm{CO}_{2}$ at $37^{\circ} \mathrm{C}$ with $100 \mathrm{ng} / \mathrm{mL}$ murine recombinant macrophage colony-stimulating factor (PeproTech Inc., Rocky Hill, NJ) for 6 days. For osteoclastic differentiation, cells were suspended in Dulbecco's modified Eagle's medium containing $10 \%$ fetal bovine serum and then seeded at $1 \times 10^{5}$ cells per well in 24-well culture plates over $13-\mathrm{mm}$ glass coverslips. Cells were then stimulated with $50 \mathrm{ng} / \mathrm{mL}$ murine recombinant RANKL (PeproTech Inc.) and treated with 10,20 , and $40 \mathrm{ng} / \mathrm{mL}$ of recombinant IL-33 (BioLegend, San Diego, CA) for 4 days. After 7 days of stimulus, cells were stained by TRAP using commercial kit (Sigma-Aldrich) following the manufacturer's instructions. TRAP-positive and TRAP-negative cells were counted in 10 nonconsecutive fields, and results were expressed as percentage of TRAP-positive cells per field. For the pit resorption assay, cells were plated on Corning Osteo Assay Surface (Corning Life Sciences, Corning, NY), and pit formation was evaluated after 10 days. Data were expressed as number of pits per field. Samples stimulated with RANKL or with RANKL and IL-33 were also harvested after 5 days for mRNA extraction, as described above.

\section{Statistical Analysis}

Results were expressed as means \pm SEM. Because data sets presented a normal distribution (Kolmogorov-Smirnov), a one-way analysis of variance was used to analyze differences among groups, followed by a Newman-Keuls multiple comparison post hoc test to evaluate and compare the differences. A Kolmogorov-Smirnov test and an unpaired Student's $t$-test were used to evaluate and compare the differences between two groups. The data obtained from all evaluations were processed with GraphPad Prism version 5.01 (GraphPad Software, San Diego, CA). The level of significance for all statistical tests was predetermined at $5 \%$.

\section{Results}

\section{St2 ${ }^{-/-}$Mice Exhibit Reduced Bone Mineral Density}

To assess whether lack of ST2 interferes with bone phenotype under steady-state conditions, MicroCT was used 

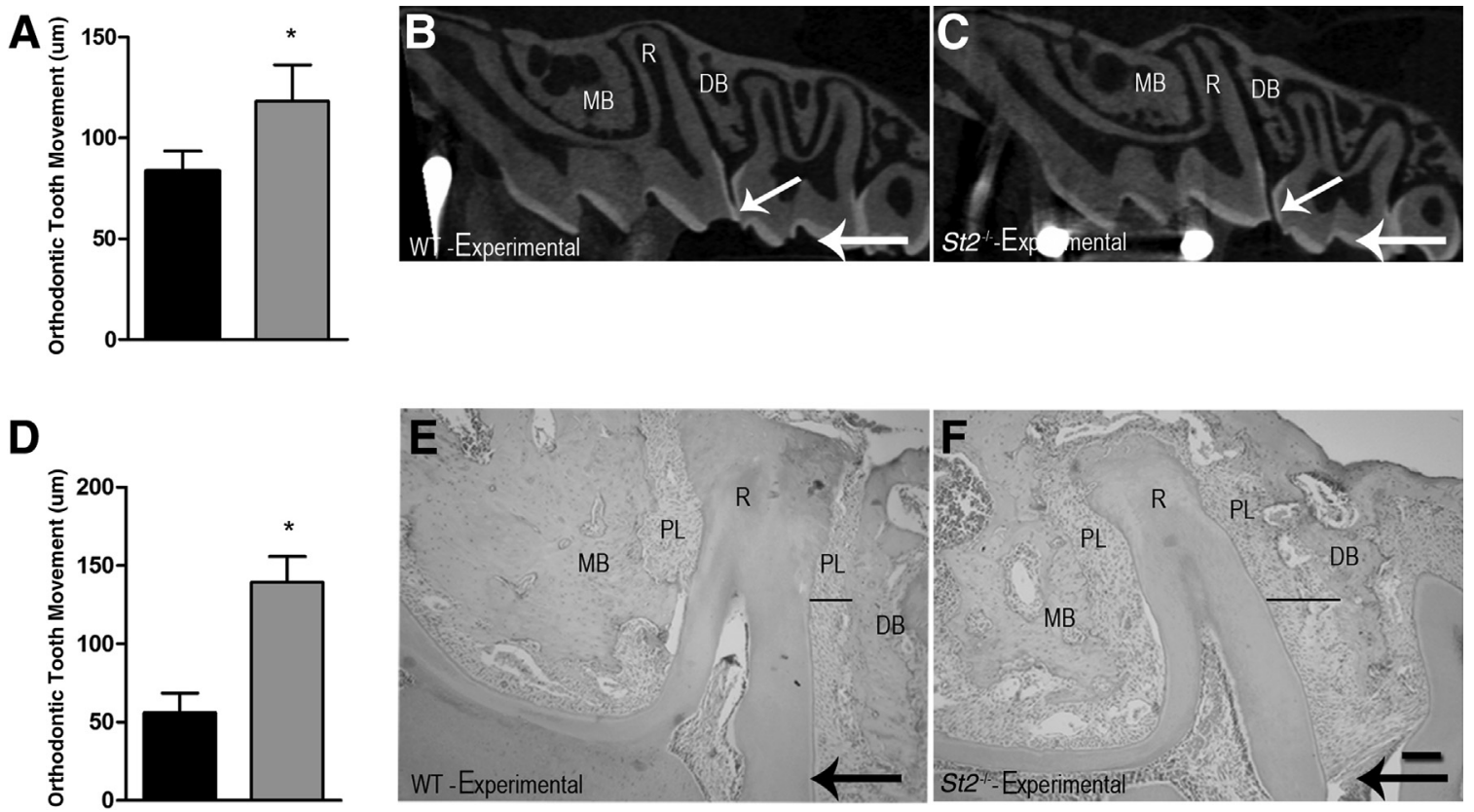

Figure 2 Amount of tooth movement. Amount of tooth movement in wild-type (WT; black bars) and St2 ${ }^{-/-}$(gray bars) mice measured by microcomputed tomography (MicroCT; A) and histology (D). MicroCT (B and C) and histological (E and $\mathbf{F}$ ) changes related to orthodontic tooth movement in WT and $\mathrm{St2}^{-/-}$mice 12 days after mechanical loading. White angulated arrows indicate the space between the crows of the first and second molars; black lines, periodontal ligament space between the distal root and the distal bone; black and white straight arrows, the direction of orthodontic tooth movement. Data were expressed as means $\pm \mathrm{SEM}(\mathbf{A}$ and $\mathbf{D}) .{ }^{*} P<0.05$. Scale bar $=400 \mu \mathrm{m}$. DB, distal alveolar bone; $\mathrm{MB}$, mesial alveolar bone; $\mathrm{PL}$, periodontal ligament; $R$, root.

to analyze bone parameters. Comparison of maxillary bones revealed significant reduction of bone volume percentage in $S t 2^{-1-}$ in relation to WT (Table 1). In contrast, trabecular number $\left(\mu \mathrm{m}^{-1}\right)$, trabecular separation $(\mu \mathrm{m})$, and bone surface $\left(\mu \mathrm{m}^{2}\right)$ showed no significant difference (Table 1). Some parameters were modified in the proximal femurs of $S t 2^{-1-}$ mice when compared with WT mice, including trabecular number $\left(\mu \mathrm{m}^{-1}\right)$, bone volume $(\%)$, and bone surface $\left(\mu \mathrm{m}^{2}\right)$ (Table 1). St $2^{-1-}$ mice also demonstrated greater trabecular separation $(\mu \mathrm{m})$ when compared with WT animals (Table 1). These differences are consistent with reduced bone mineral density in $\mathrm{St}^{-/-}$mice under steady-state conditions, suggesting a role for ST2 in physiological bone homeostasis.

\section{Mechanical Stimulus Induces IL-33 and ST2 Production}

Next, we analyzed if mechanical force triggers IL-33 and ST2 expression, by using in vivo and in vitro approaches. A significant increase of IL-33 was detected in periodontal tissues at 72 hours after force application (Figure 1A). In addition, mechanical force induced stronger ST2 immunostaining in periodontal ligament and bone marrow cells (Figure 1D) than those from the control group (Figure 1B). No other differences in ST2 expression between control and experimental groups were noticed in maxillary tissues (Figure 1, B-E).

In vitro, exposure of MC3T3-E1 osteoblastic cells to flow resulted in greater expression of IL-33 and ST2 mRNA when compared with the cells evaluated under static conditions (Figure 1, F and G).

\section{Bone Resorption Is Increased in St2 ${ }^{-/-}$Mice Subjected to Mechanical Loading}

Because there was an increase of the expression of IL-33 and ST2 after application of force, we evaluated the relevance of these molecules to bone resorption induced by mechanical loading in $S t 2^{-/-}$mice. Mechanical loading induced significant tooth movement at day 12 after the beginning of the experiment, as shown by MicroCT and histomorphometry (Figure 2, A-F). An increased space between the crows of the first and second molars was seen in MicroCT images (Figure 2, B and C). An increase of the periodontal ligament space between the distal root and the distal bone of mice subjected to OTM was also seen in MicroCT images (Figure 2, B and C) as well as histological sections (Figure 2, E and F). There was a significant amount of tooth movement in WT and $S t 2^{-1-}$ animals when compared with respective controls, but there was greater tooth movement in $S t 2^{-1-}$ than in WT mice (Figure 2, A and D). In addition, the absence of ST2 led to an increase of TRAP-positive osteoclast numbers and resorption lacunae in the mesial bone of distal-buccal root (Figure 3, A-D). Disruption of bone-lining cells and reduction of osteoblast numbers at the distal bone of distal-buccal root was consistently seen in $S t 2^{-/-}$in comparison to WT mice (Figure 3, E-H). 


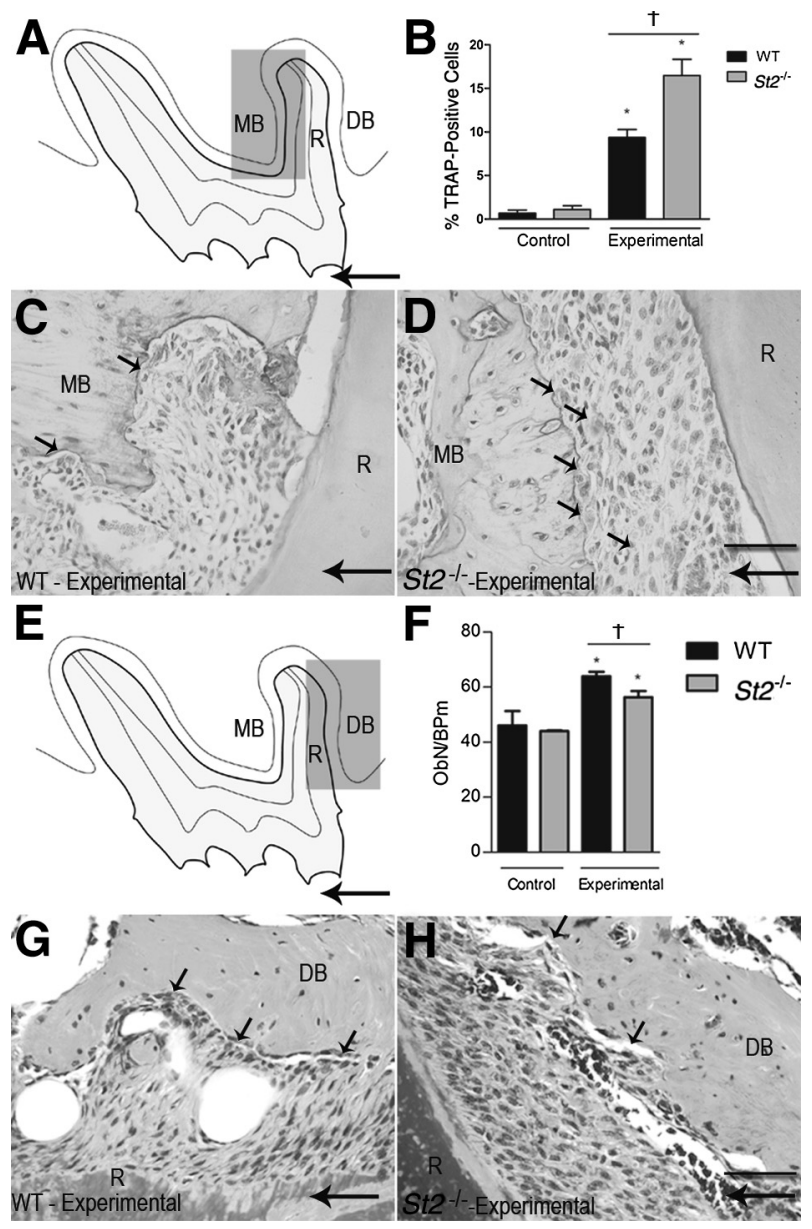

Figure 3 Number of tartrate-resistant acid phosphatase (TRAP)positive cells and osteoblasts. A: Scheme showing the compression site (in gray) used for TRAP-positive cells count. B-D: Quantification (B) and representative histological sections of TRAP-positive osteoclasts of wild-type (WT; C) and St2 ${ }^{-/}$(D) mice 12 days after mechanical loading. Black angulated arrows indicate TRAP-positive cells. E: Scheme showing the tension site (gray rectangle) used for osteoblast count. F-H: Quantification (F) and representative histological sections of osteoblasts of WT $(\mathbf{G})$ and St2 ${ }^{-/}(\mathbf{H})$ mice 12 days after mechanical loading. Black angulated arrows show bone-lining osteoblasts; black straight arrows, the direction of orthodontic tooth movement. Data were expressed as means \pm SEM (B and $\mathbf{F}$ ). ${ }^{*} P<0.05$ comparing control group with the respective experimental group; ${ }^{\dagger} P<0.05$ comparing WT with St2 ${ }^{-1-}$ experimental groups. Scale bar $=100 \mu \mathrm{m}$ (C, D, G, and H). DB, distal alveolar bone; MB, mesial alveolar bone; $R$, root.

\section{IL-33/ST2 Affects Apoptosis in Periodontal Tissues}

Because there was an increase of osteoclasts and a reduction of osteoblasts in $S t 2^{-1-}$ mice, we investigated further if ST2 interfered with cell death in the periodontium. There was a reduction in the number of apoptotic cells, including periodontal ligament cells and osteoclasts, in $\mathrm{St}^{-1-}$ mice when compared with WT mice at day 12 after application of force (Figure 4, $\mathrm{A}-\mathrm{C}$ ). Control periodontal tissues (not subjected to mechanical force) from $S t 2^{-/-}$mice also exhibited less apoptotic cells than those from WT mice (data not shown).

Increase in the Expression of Osteoclast Markers in Periodontium of $S t 2^{-/-}$Mice

Considering that $S t 2^{-1-}$ mice had increased OTM and osteoclast counts, we evaluated if expression of osteoclast

A
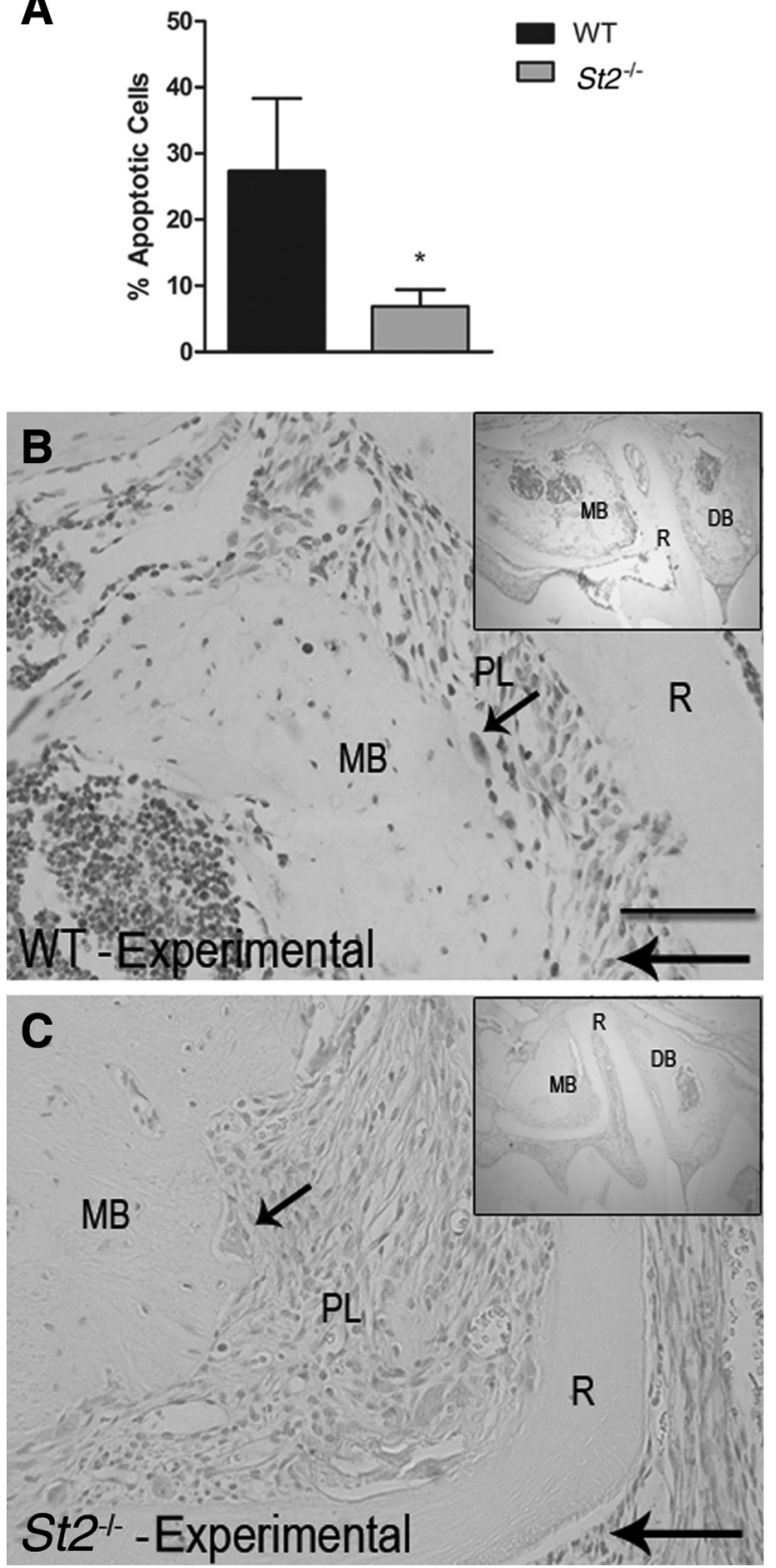

Figure 4 Number of apoptotic cells in periodontal ligament. A: Percentage of apoptotic cells 12 days after mechanical loading. B and C: Representative images of apoptotic cells in periodontium of wild-type (WT; B) and St2 ${ }^{-/-}$(C) mice. Black angulated arrows indicate osteoclasts in apoptosis; black straight arrows, the direction of tooth movement. Data were expressed as means \pm SEM (B and $\mathbf{C}) .{ }^{*} P<0.05$. Scale bar $=100 \mu \mathrm{m}(\mathbf{B}$ and $\mathbf{C})$. Original magnification, $\times 10$ (B and C, insets). DB, distal alveolar bone; MB, mesial alveolar bone; $\mathrm{PL}$, periodontal ligament; $\mathrm{R}$, root. 

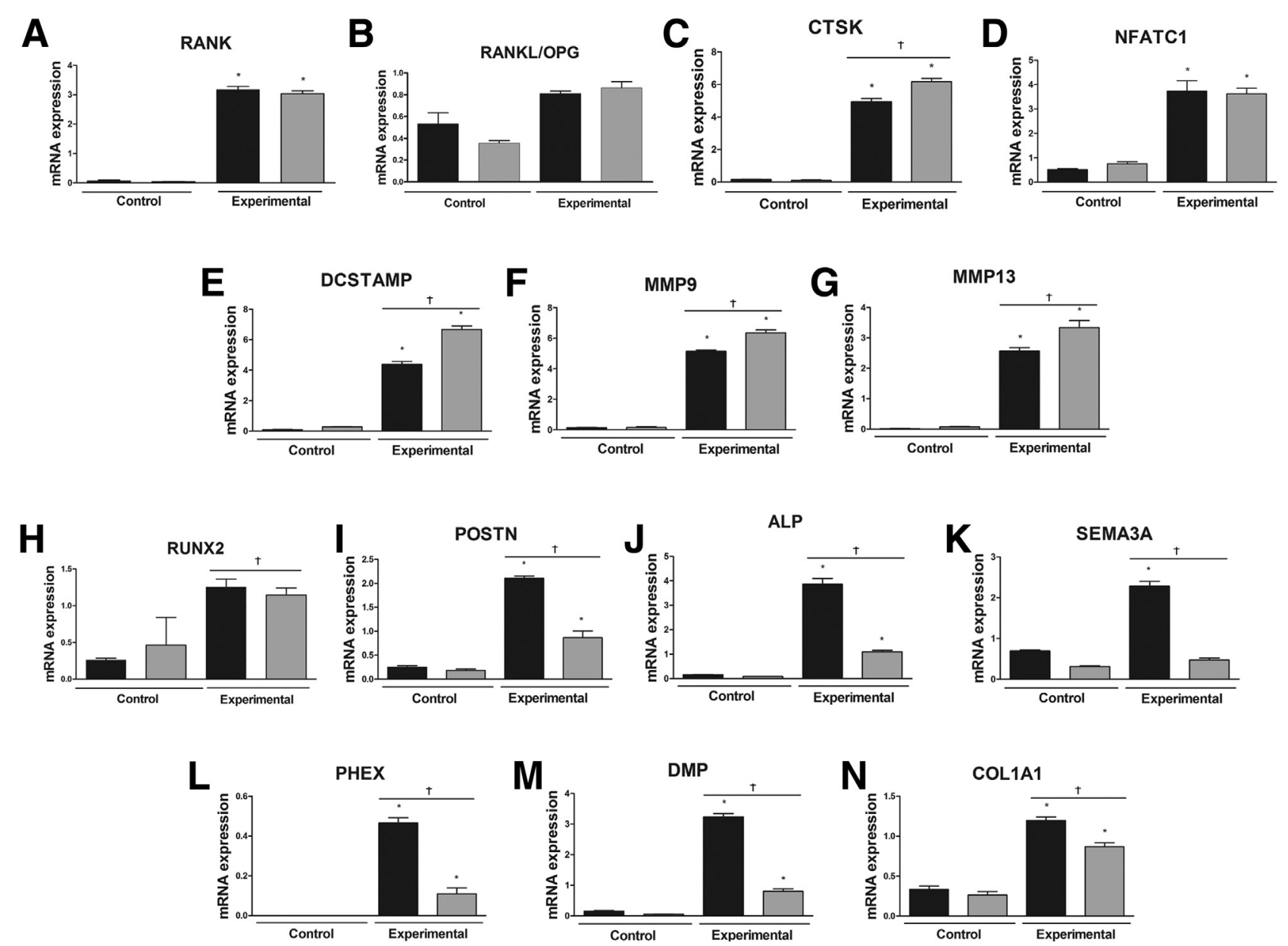

Figure 5 mRNA expression of osteoclast and osteoblast markers in wild-type (WT; black bars) and St2 ${ }^{-/-}$(gray bars) alveolar bone and periodontium samples after 72 hours of mechanical loading. A-G: The inserts on the osteoclast markers section show the expression of these markers in the compression sides. $\mathbf{H}-\mathbf{N}$ : The inserts on the osteoblast markers section show the expression of these markers in the tension sides. Data are expressed as means \pm SEM $(\mathbf{A}-\mathbf{N})$. ${ }^{*} P<0.05$ comparing control with the respective experimental group; ${ }^{\dagger} P<0.05$ comparing WT with St2 ${ }^{-/-}$experimental groups. ALP, alkaline phosphatase; COL1A1, collagen, type I, $\alpha 1$; DMP, dentin matrix acidic phosphoprotein; 0PG, osteoprotegerin; PHEX, phosphateregulating endopeptidase homolog, X-linked; POSTN, periostin; RANK, receptor activator of NF- $K B$; RUNX2, runt-related transcription factor 2; SEMA3A, semaphorin-3A.

markers would be consistently affected by the absence of ST2. At 12 hours after mechanical loading, there were no significant differences in mRNA expression of evaluated parameters when comparing mice not subjected to mechanical loading (0 hours) or between WT and $S t 2^{-l-}$ mice subjected to loading (data not shown). There was no significant difference in expression of RANK, the ratio between RANKL and osteoprotegerin, or nuclear factor of activated $\mathrm{T}$ cells, cytoplasmic, calcineurin-dependent 1 in the periodontal compression sites of WT and St2 ${ }^{-/-}$mice (Figure 5, $A-G)$. In contrast, there was greater expression of matrix metalloproteinases 9 and 13, dendritic cell-specific transmembrane protein, and cathepsin $\mathrm{K}$ at compression sites of $S t 2^{-1-}$ than WT mice at 72 hours of mechanical loading (Figure 5, A-G).

There was no significant difference in mRNA expression of osteoblast markers among all groups at 12 hours after mechanical loading (data not shown). In contrast, mRNA expression of periostin, alkaline phosphatase, semaphorin-3A, phosphate-regulating endopeptidase homolog, $\mathrm{X}$-linked, dentin matrix acidic phosphoprotein, and collagen, type I, $\alpha 1$ was lower in the periodontal tension sites of $S t 2^{-\prime-}$ than WT mice after 72 hours (Figure 5, I-N). The expression of runt-related transcription factor 2 was similar in both groups (Figure $5 \mathrm{H}$ ). These findings are in agreement with and may account for the pro-osteoclastic and anti-osteoblastic scenario in the periodontal milieu of mice lacking ST2.

\section{IL-33 Inhibits 0steoclast Differentiation and Activity in the Presence of RANKL in Vitro}

In vitro experiments were performed to confirm the observed inhibitory effect of IL-33/ST2 on bone resorption. The treatment of bone marrow-derived osteoclasts with IL-33 resulted in decreased formation of TRAP-positive osteoclasts (Figure 6A) and reduced resorption pits when compared with RANKL-stimulated cells (Figure 6, B-F). 
A
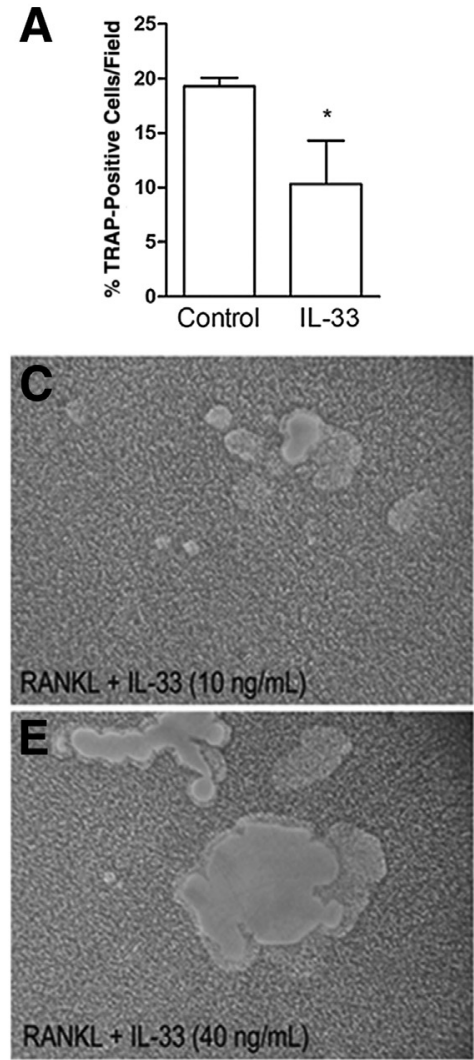
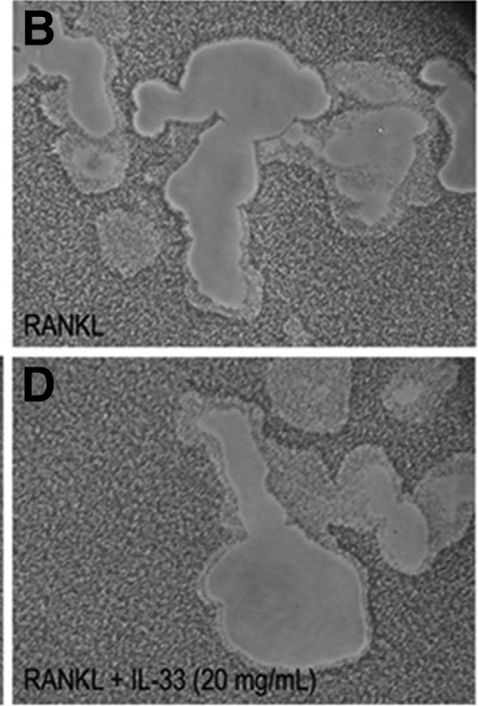

$\mathbf{F}$

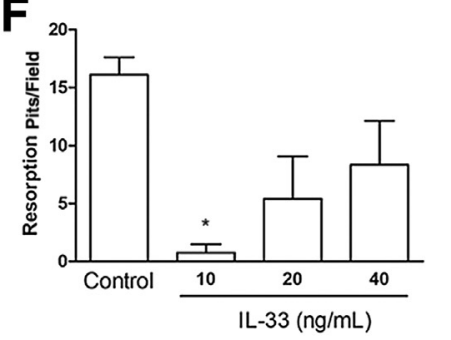

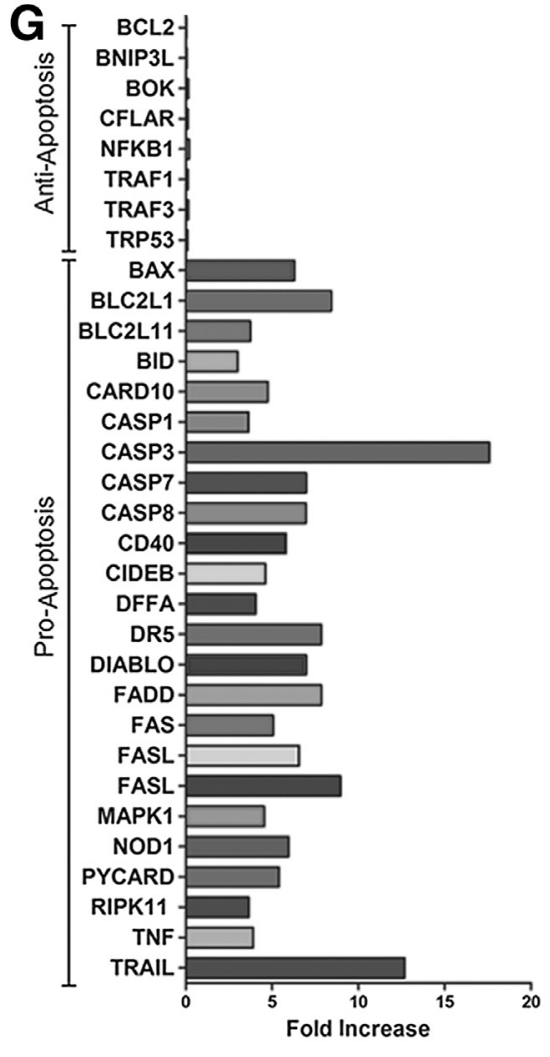

Figure 6 Tartrate-resistant acid phosphatase (TRAP)-positive cells, resorption pits, and expression of apoptotic markers in culture of bone marrow cells from BALB/c mice stimulated with receptor activator of NF- $\mathrm{B} B$ ligand (RANKL) or with RANKL and $20 \mathrm{ng} / \mathrm{mL}$ IL-33. A: Number of TRAP-positive cells after treatment with RANKL and macrophage colony-stimulating factor (M-CSF; control) and IL-33. B-E: Resorption pit formation after treatment with RANKL (B), RANKL + IL-33 (10 ng/mL; C), RANKL + IL-33 (20 ng/mL; D), and RANKL + IL-33 (40 ng/mL; E). F: Resorption field in culture of osteoclasts. G: Expression of pro- and anti-apoptotic molecules by osteoclasts in culture treated with $20 \mathrm{ng} / \mathrm{mL} \mathrm{IL-33.} \mathrm{All} \mathrm{markers} \mathrm{exhibit} \mathrm{statistically} \mathrm{significant} \mathrm{expression} \mathrm{compared} \mathrm{with}$ controls. The values were submitted to correction of Benjamini and Hochberg test. ${ }^{*} P<0.05$ between experimental groups with its respective control, oneway ANOVA and Newman-Keuls multiple comparison test. BAX, BCL2-associated X protein; BCL2, B cell lymphoma 2; BID, BCL2-like 11, BH3 interacting-domain death; BNIP3L, BCL2/adenovirus E1B 19 KDa interacting protein 3-like; BOK, BCL2-related ovarian killer; CFLAR, CASP8 and FADD-like apoptosis regulator; CARD, C-terminal caspase-recruitment domain; CASP, caspase; CIDEB, cell death-inducing DFFA-like effector b; DFFA, DNA fragmentation factor 45 KDa alpha polypeptide; DR5, death receptor 5; FADD, fas-associated protein with death domain; MAPK1, mitogen-activated protein kinase 1; NOD1, nucleotide-binding oligomerization domain-containing protein 1; RIPK11, receptor-interacting serine/threonine-protein kinase 11; TNF, tumor necrosis factor; TRAIL, TNF-related apoptosis-inducing ligand; TRAF, TNF receptor-associated factor; TRP53, transformation related protein 53.

\section{IL-33 Increases the Expression of Apoptotic Markers by Osteoclasts in Vitro}

Because we have observed a reduced number of apoptotic cells in periodontium of $S t 2^{-1-}$ mice, we next analyzed if IL-33 administration affects osteoclast apoptosis in vitro. We observed that the treatment of bone marrow-derived osteoclasts with IL-33 induced significant expression of positive regulators of apoptosis, including caspases (CASPs) 1,3, 7, and 8. Moreover, mRNA expression of markers that are considered negative regulators of apoptosis, BCL2 and NFKB1, was reduced in the group treated with RANKL and IL-33 when compared with RANKL-stimulated osteoclasts (Figure 6G).

\section{Discussion}

Bone is a dynamic tissue, ${ }^{1}$ and its integrity and homeostasis involve balance between bone resorption and formation. ${ }^{3}$
Some molecules are capable of influencing these events, among them IL-33, the ligand for ST2. ${ }^{14-16}$ Our results confirmed ST2 expression by bone and periodontal ligament cells and also indicate mechanical stimulus as an inducer of IL-33/ST2 expression. Consistently with the in vivo findings, there was expression of both molecules in MC3T3 cells, a well-characterized cell line with osteoblastic phenotype ${ }^{12,20}$ subjected to force in vitro. In the absence of ST2/IL-33, alveolar bone architecture is disrupted both under physiological conditions and mechanical stimulation, suggesting an essential role for ST2/IL-33 in maintenance of bone homeostasis. Accordingly, IL-33/ST2 functions as a suppressor of osteoclast differentiation by regulating cell death. To the best of our knowledge, this is the first study to demonstrate that the control of bone resorption by IL-33/ ST2 is linked to osteoclast apoptosis.

To better define the bone phenotype of ST2-deficient mice, proximal femurs and maxillae were evaluated by MicroCT. Our 


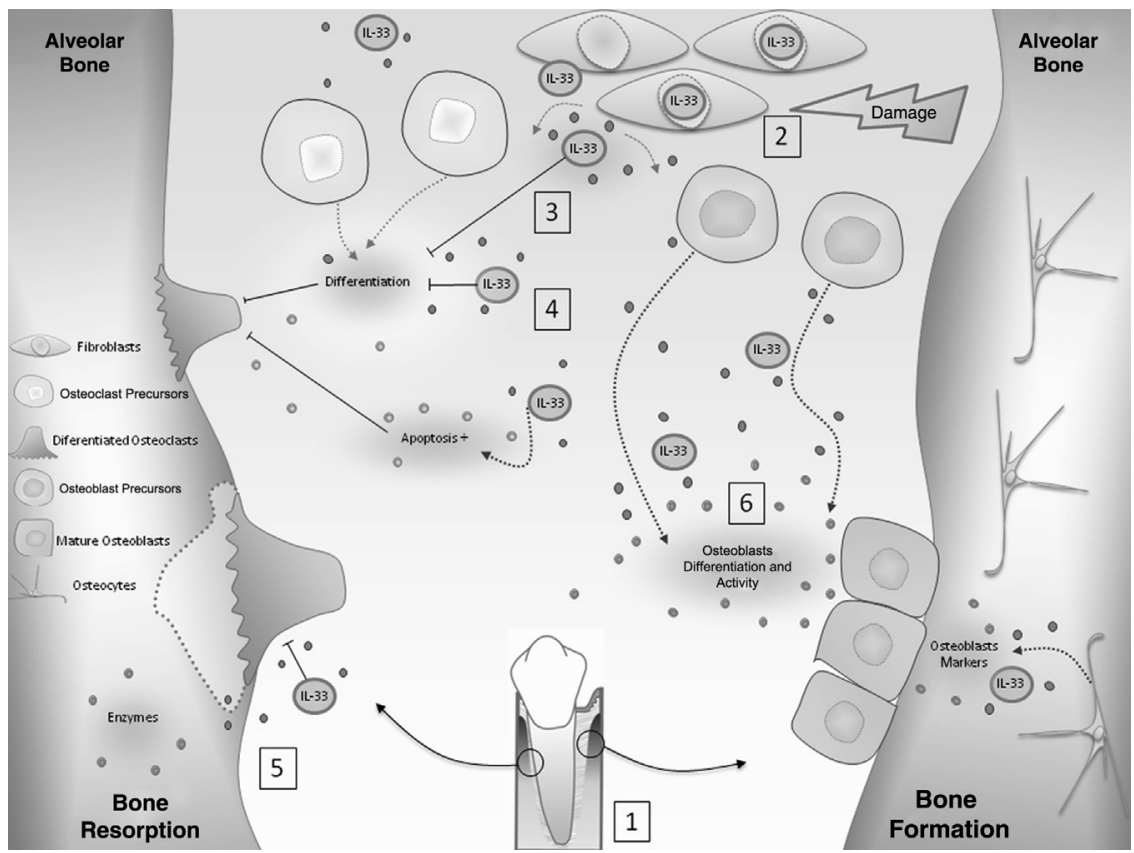

Figure 7 Schematic model of IL-33/ST2 role in bone remodeling. 1 , Tooth movement inside alveolus triggered by mechanical force generates resorption and apposition sites. 2, Cell damage generated by tension and compression of periodontal ligament induces IL-33 release. 3 to 5 , Resorption sites. 3, IL-33 inhibits osteoclast differentiation and activity. 4, IL-33 induces osteoclast apoptosis. 5, IL-33 reduces the expression of enzymes, such as matrix metalloproteinases and cathepsin K, decreasing bone resorption. 6, Apposition sites. IL-33 stimulates osteoblast differentiation and activity and osteocyte activity.

results are in agreement with a previous study that shows decreased bone mineral density in femurs of $S t 2^{-/-}$mice. ${ }^{14}$ In contrast, most bone parameters in maxillae were similar between WT and $S t 2^{-/-}$mice. Interestingly, maxillary bones showed less pronounced differences related to bone mineral density than femurs, probably because maxillary bone development is distinct from axial and appendicular skeleton ${ }^{26}$ and exhibits reduced physiological remodeling when compared with long bones. ${ }^{27}$ The latter observation may explain the fact that maxillary bones are less influenced by ST2 deficiency than long bones. Furthermore, age-related changes affect distinct bones, resulting in particular bone phenotypes. ${ }^{28}$ In this study, adult mice (between weeks 6 and 10 of age) were used preferentially because they have completed bone maturation. ${ }^{28}$ However, there are no reports in the literature associating different maturation pattern in maxillae with age of mice.

Our data also demonstrated increased bone resorption and greater number of osteoclasts, leading to greater tooth movement in the absence of IL-33/ST2 interaction. In our study, we also found that $S t 2^{-/-}$mice had a reduced number of osteoblasts in the alveolar bone when compared with WT mice. Therefore, both cell types appear to be affected by the absence of ST2 in the alveolar bone. These results are consistent with a previous study demonstrating that IL-33 inhibits osteoclast differentiation both in vivo and in vitro. ${ }^{15}$ However, another study has previously reported that IL-33 did not affect osteoblast differentiation in vitro. ${ }^{12,14}$ Moreover, transgenic mice overexpressing IL-33 do not exhibit differences in osteoblast numbers and bone formation under steady-state conditions. ${ }^{18}$

No previous data on bone marrow osteoblastogenesis of $S t 2^{-1-}$ mice are available. Molecular analyses of genes related to osteoclastogenesis support the idea that osteoclast activity is increased in the absence of ST2. Indeed, proresorptive markers matrix metalloproteinases 9 and 13, dendritic cell-specific transmembrane protein, and cathepsin $\mathrm{K}$ were increased in $S t 2^{-/-}$mice after mechanical loading. The increase occurred particularly at the compression side, which is predominantly characterized by resorptive activity. ${ }^{29,30}$ These results are consistent with a previous study demonstrating that osteoclasts differentiated in the presence of IL-33 have reduced expression of osteoclastogenic molecules, such as osteoclast-associated receptor, nuclear factor of activated T cells, cytoplasmic, calcineurin-dependent 1 , and calcitonin receptor. ${ }^{14,31}$

Osteoclastogenesis and bone resorption are positively regulated by RANKL through its binding to RANK. ${ }^{32,33}$ Our data showed no significant difference in RANK or in the RANKL/osteoprotegerin ratio comparing WT with $S t 2^{-1-}$ groups. In accordance, previous studies have shown that IL-33/ST2 influences bone remodeling independently of the RANK/RANKL pathway. ${ }^{14,17,21}$

Osteoblast numbers in periodontium subjected to force were reduced in $S t 2^{-/-}$mice. Consistent with this, osteoblast markers periostin, alkaline phosphatase, phosphateregulating endopeptidase homolog, X-linked, dentin matrix acidic phosphoprotein, and collagen, type I, $\alpha 1$ were also decreased in our experiments. This observation suggests reduced osteoblast differentiation or activity and might be linked to reduced expression of semaphorin-3A, which is produced by osteoblasts and promotes their differentiation. ${ }^{33}$ Moreover, semaphorin-3A inhibits differentiation of osteoclasts. ${ }^{34}$ Therefore, taken together, our results suggest that ST2 deficiency does affect osteoclast and osteoblast numbers and function in certain types of bone, in our case the alveolar bone, and this may contribute to the role of IL-33/ST2 on bone remodeling under steadystate conditions and after application of force. 
In vitro experiments revealed an inhibitory effect of IL-33 on osteoclast formation and activity, as previously observed. ${ }^{14,15}$ Controversially, one study described IL-33 as a potent stimulus for osteoclast differentiation from human CD $14^{+}$monocytes. ${ }^{17}$ Another study showed no difference in osteoclast generation when bone marrow cells were taken from $S t 2^{-/-}$mice. ${ }^{15}$ These divergences can be associated with the different derivation of the cells used in each study. Furthermore, our results and previous studies ${ }^{15,21}$ suggest that the major effects of IL-33 are in osteoclasts. Therefore, our study supports the anti-osteoclastogenic effect of IL-33.

To evaluate if the anti-osteoclastogenic effects of IL-33 are associated with the induction of cell death, we analyzed the expression of apoptosis regulators in osteoclasts treated with IL-33 in vitro. We showed that the expression of antiapoptotic molecules is lower when compared with proapoptotic molecules. Two types of apoptosis (types I and II; alias extrinsic and intrinsic types, respectively) are recognized. ${ }^{35}$ In type I apoptosis, CASP8 triggers the activation of CASPs 3 and 7 without the involvement of the intrinsic pathway. In type II apoptosis, CASP8 cleaves and activates the pro-apoptotic BCL2 family member BID. ${ }^{35}$ Our results indicated that osteoclasts treated with IL-33 exhibited an increase in the expression of pro-apoptotic factors of both type I (FAS, FASL, tumor necrosis factor-related apoptosis-inducing ligand, and tumor necrosis factor- $\alpha$ ) and type II (FAS and BID) pathways. The interaction between type I molecules is followed by activation of downstream effectors (CASPs 3, 6, and 7) that directly induce cell death or cleavage of the BCL2 family member BID, hence also activating the intrinsic apoptotic pathway. ${ }^{36}$ Therefore, IL-33 appears to activate both types of apoptosis in osteoclasts. Because IL-33 induces osteoclast apoptosis, a reduced number of these cells may explain the inhibition by IL-33 of bone resorption in vitro. It may also explain the enhanced bone resorption observed in $S t 2^{-/-}$mice subjected to force-induced bone remodeling.

Figure 7 depicts a hypothetical model for the action of IL-33. IL-33 is released as an alarmin when a mechanical stimulus induces damage of periodontal cells. On release, IL-33 enhances osteoblast accumulation, inhibits osteoclast differentiation and activity, and induces osteoclast apoptosis, resulting in decreased bone resorption and consequent tooth movement. Therefore, IL-33/ST2 plays a fundamental role in controlling alveolar bone remodeling. The bone-sparing effects of $\mathrm{IL}-33$ suggest that therapies that decrease IL-33/ST2 function may be associated with enhanced bone loss under certain conditions.

\section{Acknowledgments}

We thank Christopher Jacobs and Julia Chen (Columbia University, New York, NY) for help with osteoblast cultures and Maria Cássia Ferreira Aguiar and Daniela Cotta Ribeiro (Universidade Federal de Minas Gerais) for help with the terminal deoxynucleotidyl-transferase-mediated dUTPFITC nick-end labeling assay.

\section{References}

1. Raggatt LJ, Partridge NC: Cellular and molecular mechanisms of bone remodeling. J Biol Chem 2010, 285:25103-25108

2. Kaku M, Kohno S, Kawata T, Fujita I, Tokimasa C, Tsutsui K, Tanne K: Effects of vascular endothelial growth factor on osteoclast induction during tooth movement in mice. J Dent Res 2001, 80:1880-1883

3. Davidovitch Z: Tooth movement. Crit Rev Oral Biol Med 1991, 2: $411-450$

4. Matkovic V: Calcium metabolism and calcium requirements during skeletal modeling and consolidation of bone mass. Am J Clin Nutr 1991, 54:245S-260S

5. Garlet GP, Cardoso CRB, Campanelli AP, Ferreira BR, AvilaCampos MJ, Cunha FQ, Silva JS: The dual role of p55 tumour necrosis factor- $\alpha$ receptor in Actinobacillus actinomycetemcomitans-induced experimental periodontitis: host protection and tissue destruction. Clin Exp Immunol 2006, 147:128-138

6. Miller AM: Role of IL-33 in inflammation and disease. J Inflamm (Lond) 2011, 8:22

7. Schmitz J, Owyang A, Oldham E, Song Y, Murphy E McClanahan TK, Zurawski G, Moshrefi M, Qin J, Li X, Gorman DM, Bazan JF, Kastelein RA: IL-33, an interleukin-1-like cytokine that signals via the IL-1 receptor-related protein ST2 and induces T helper type 2-associated cytokines. Immunity 2005, 23:479-490

8. Chackerian AA, Oldham ER, Murphy EE, Schmitiz J, Pflanz S, Kastelein RA: IL-1 receptor accessory protein and ST2 comprise the IL-33 receptor complex. J Immunol 2007, 179:2551-2555

9. Ohno T, Oboki K, Kajiwara N, Morii E, Aozasa K, Flavell RA, Okumura K, Saito H, Nakae S: Caspase-1, caspase-8, and calpain are dispensable for IL-33 release by macrophages. J Immunol 2009, 183: 7890-7897

10. Carriere V, Roussel L, Ortega N, Lacorre DA, Americh L, Aguilar L, Bouche G, Girard JP: IL-33, the IL-1-like cytokine ligand for ST2 receptor, is a chromatin-associated nuclear factor in vivo. Proc Natl Acad Sci U S A 2007, 104:282-287

11. Na HJ, Hudson SA, Bochner BS: IL-33 enhances Siglec-8 mediated apoptosis on human eosinophilis. Cytokine 2012, 57:168-174

12. Saidi S, Bouri F, Lencel P, Duplomb L, Baud'huin M, Delplace S, Leterme D, Miellot F, Heymann D, Hardouin P, Palmer G, Magne D: IL-33 is expressed in human osteoblasts, but has no direct effect on bone remodeling. Cytokine 2011, 53:347-354

13. Schett G: Effects of inflammatory and anti-inflammatory cytokines on the bone. Eur J Clin Invest 2011, 41:1361-1366

14. Schulze J, Bickert T, Beil FT, Zaiss MM, Albers J, Wintges K, Streichert T, Klaetschke K, Keller J, Hissnauer T, Spiro AS, Gessner A, Schett G, Amling M, McKenzie ANJ, Horst AK, Schinke T: Interleukin-33 is expressed in differentiated osteoblasts and blocks osteoclast formation from bone marrow precursor cells. J Bone Miner Res 2011, 26:704-717

15. Zaiss MM, Kurowska-Stolarska M, Bohm C, Gary R, Scholtysek C, Stolarski B, Reilly J, Kerr S, Millar NL, Kamradt T, McInnes IB, Fallon PG, David J, Liew FY, Schett G: Interleukin (IL)-33 shifts the balance from osteoclast to alternatively- activated macrophage differentiation and protects from TNFa-mediated bone loss. J Immunol 2011, 186:6097-6105

16. Tominaga $\mathrm{S}$ : A putative protein of a growth specific cDNA from BALB/c-3T3 cells is highly similar to the extracellular portion of mouse interleukin 1 receptor. FEBS Lett 1989, 258:301-304

17. Mun SH, Ko NY, Kim HS, Kim JW, Kim do K, Kim AR, Lee SH, Kim YG, Lee CK, Lee SH, Kim BY, Beaven MA, Kim YM, Choi WS: Interleukin-33 stimulates formation of functional osteoclasts from human CD14(+) monocytes. Cell Mol Life Sci 2010, 67:3883-3892 
18. Keller J, Catala-Lehnen P, Wintges K, Schulze J, Bickert T, Ito W, Horst AK, Amling M, Schinke T: Transgenic over-expression of interleukin-33 in osteoblasts results in decreased osteoclastogenesis. Biochem Biophys Res Commun 2012, 417:217-222

19. Saidi S, Magne D: Interleukin-33: a novel player in osteonecrosis of the femoral head? Joint Bone Spine 2011, 78:550-554

20. Werenskiold AK, Rossler U, Lowel M, Schmidt J, Heermeier K, Spanner MT, Strauss PG: Bone matrix deposition of T1, a homologue of interleukin 1 receptors. Cell Growth Differ 1995, 6:171-177

21. Saleh H, Eeles D, Hodge JM, Nicholson GC, Gu R, Pompolo S, Gillespie MT, Quinn JMW: Interleukin-33, a target of parathyroid hormone and oncostatin $\mathrm{m}$, increases osteoblastic matrix mineral deposition and inhibits osteoclast formation in vitro. Endocrinology 2011, 152:1911-1922

22. Buduneli N, Özçaka Ö, Nalbantsoy A: Interleukin-33 levels in gingival crevicular fluids, saliva or plasma do not differentiate chronic periodontitis. J Periodontol 2012, 83:362-368

23. Köseoğlu S, Hatipoğlu M, Sağlam M, Enhoş S, Esen HH: Interleukin33 could play an important role in the pathogenesis of periodontitis. J Periodontal Res 2015, 50:525-534

24. Taddei SRA, Moura AP, Andrade I Jr, Garlet GP, Garlet TP, Teixeira MM, da Silva TA: Experimental model of tooth movement in mice: a standardized protocol for studying bone remodeling under compression and tensile strains. J Biomech 2012, 45: $2729-2735$

25. Kwon RY, Jacobs CR: Time-dependent deformations in bone cells exposed to fluid flow in vitro: investigating the role of cellular deformation in fluid flow-induced signaling. J Biomech 2007, 40:3162-3168

26. Chai Y, Maxson RE Jr: Recent advances in craniofacial morphogenesis. Dev Dyn 2006, 235:2353-2375
27. Mavropoulos A, Rizzoli R, Ammann P: Different responsiveness of alveolar and tibial bone to bone loss stimuli. J Bone Miner Res 2007, 22:403-410

28. Glatt V, Canalis E, Stadmeyer L, Bouxsein ML: Age-related changes in trabecular architecture differ in female and male C57BL/6J mice. J Bone Miner Res 2007, 22:1197-1207

29. Krishnan V, Davidovitch Z: Cellular, molecular, and tissue-level reactions to orthodontic force. Am J Orthod Dentofacial Orthop 2006, 129:1-32

30. Wise GE, King GJ: Mechanisms of tooth eruption and orthodontic tooth movement. J Dent Res 2008, 87:414-434

31. Kiyomiya H, Ariyoshi W, Okinaga T, Kaneuji T, Mitsugi S, Sakurai T, Habu M, Yoshioka I, Tominaga K, Nishihara T: IL-33 inhibits RANKL-induced osteoclast formation through the regulation of Blimp-1 and IRF-8 expression. Biochem Biophys Res Commun 2015, 460:320-326

32. Boyce BF, Xing L: Bruton and Tec: new links in osteoimmunology. Cell Metab 2008, 7:283-285

33. Aoki S, Honma M, Kariya $\mathrm{Y}$, Nakamichi $\mathrm{Y}$, Ninomiya $\mathrm{T}$, Takahashi N, Udagawa N, Suzuki H: Function of OPG as a traffic regulator for RANKL is crucial for controlled osteoclastogenesis. J Bone Miner Res 2010, 25:1907-1921

34. Guttmann-Raviv N, Shraga-Heled N, Varshavsky A, GuimaraesSternberg C, Kessler O, Neufeld G: Semaphorin-3A and semaphorin$3 \mathrm{~F}$ work together to repel endothelial cells and to inhibit their survival by induction of apoptosis. J Biol Chem 2007, 282:26294-26305

35. Hao Z, Mak TW: Type I and type II pathways of Fas-mediated apoptosis are differentially controlled by XIAP. J Mol Cell Biol 2010, 2:63-64

36. Verbrugge I, Johnstone RW, Smyth MJ: SnapShot: extrinsic apoptosis pathways. Cell 2010, 143:1192. 1192.e1-2 